\title{
CONVENCIONALISMO Y ARTIFICIOSIDAD EN LA POESIA BUCOLICA DE LA SEGUNDA MITAD DEL SIGLO XVIII
}

Muy recientemente, un conocido investigador en materias históricas y literarias del siglo XVIII ha expresado la opinión -que pienso generalizadade que, en un cambio de perspectiva, la historia de la literatura dieciochesca sea abordada desde los géneros y subgéneros que la habitan; concediendo a este nivel (el del propio texto y su posición en la tradición) una atención antes mayoritariamente dedicada al escritor, y a lo que se conoce como estudio de las distintas etapas en el desarrollo de su creación individual ${ }^{1}$.

1. Un recorrido, dentro del género lírico, por la obra de los más significados poetas españoles de la segunda mitad del siglo XVIII evidencia una intensificación de la temática bucólica, vertida ésta, frecuentemente, en las formas típicas en que se expresa el género bucólico (églogas, idilios, pastorales); pero también en cantilenas, odas, letrillas, anacreónticas... Esta vinculación del discurso literario dieciochesco al género bucólico, presente a lo largo de toda la centuria, eclosiona como síntoma de una nueva ideología en la década de los años $70^{2}$, pero está precedida por la

1 Escribe Francisco Aguilar Piñal, «Desde luego, pienso que al tema [se refiere al estudio de la poesía filosófica de la segunda mitad del siglo XVIII] ha perjudicado el estudio por autores. Creo que, en el futuro, será mucho más fructífera la investigación por géneros y aun por subgéneros, ya que es frecuente que en un mismo autor se den todas o varias de las tendencias literarias que se cruzan en la centuria [...] No hay sino textos.» («La poesía filosófica de Cándido María Trigueros», Revista de Literatura, 85 (1981), 36.

2 Esta década es, para Joaquín Arce, la más significativa de todo el siglo ilustrado: «época de apogeo de Cadalso y del paulatino influjo de Jovellanos en la vida pública y literaria -nacidos ambos, con Iglesias, treinta años antes-, es realmente importante en la historia de las corrientes poéticas dieciochescas»y, más adelante, «Una vez más corresponden a la década de los setenta las manifestaciones más explícitas de los temas ilustrados en la lírica». (La poesía del siglo ilustrado. (Madrid, 1981), 202; 251). 
constitución en España, siguiendo el modelo italiano, de «academias arcádicas» o declaraciones teóricas en favor de la revitalización del viejo género. Declaraciones apologéticas como la que, en 1750, hace el conde de Torrepalma:

«Volverá, si la reverencia de nuestros mayores nos persuade que ha pasado, el Siglo de Oro de la poesía española y la rústica bucólica verá entre los humildes arbustos de sus felicísimas selvas nuevos Garcilasos, nuevos Boscanes, y sobre sus mirtos pastoriles levantarse el sagrado tronco de alguna minerval oliva.» ${ }^{3}$

Efectivamente, el prestigio del género entre los nuevos poetas que, de modo significativo, lo utilizan en las primeras etapas de su formación literaria, proviene de su misma antigüedad y radica en el hecho de ser éste -el «carmen bucolicum»- la más duradera creación del clasicismo. Los tratadistas clásicos, pero también los contemporáneos a los poetas que ahora tratamos, no dejan de señalar esta autoridad que le viene al género por su misma genealogía clásica ${ }^{4}$. El respeto a la configuración tradicional y poco renovada que el mismo ha tenido, veremos cómo constituye una de las claves que toda lectura moderna ha de valorar.

Si consideramos el género bucólico como una manifestación -la más importante desde el punto de vista de una recuperación arqueológica- de la ideología neoclásica ${ }^{5}$, veremos cómo la revitalización del mismo se emprende, desde luego, con los materiales que suministra la pastoral -como prosa y como lírica- del $\mathrm{XVI}^{6}$, pero también de la buć́lica clásica, incluso

3. Oración del Presidente con que se introdujo la Academia (leida el l de octubre de 1750), Cit. por N. Martin, Poesia y poetas del setecientos. (Granada, 1971), 174.

4 Así, entre otros, Herrera que escribe que las composiciones bucolicas eson el género más antiguo de poesiam. (Anotaciones a las obras de Garcilaso de la Vega. Ed. de Gallego Morell -Madrid, 1973-, 504) o Luzán: Es cierto que esta especie de poesía [la pastoril] es de los primeros que se inventaron.

5. Ya Guillermo Camero (Antologla de la poesía prerromántica española -Barcelona, 1970- 14) contempla el género pastoril como manifestación del neoclasicismo: abl problema más especioso haya sida quizá el enjuiciamiento de los poemas de tema pastoril, concretamente los escritos por Meléndez, puesto que églogas, anacreónticas e idilios son formas plenamente neoclasicas.

6 El carácter voluntariamente nexual que presentan las realizaciones dieciochescas con respecto a las del Renacimiento ha sido puesto en evidencia de un modo muy particular por Lázaro Carreter, F* , Las ideas lingüísticas durante el siglo XVIII", Revista de Filología Española $\rightarrow$ anejo al $n^{*} 48-(1949), 239$ y ss. 
en sus más remotos antecedentes: Teórrito ${ }^{7}$ y, por supuesto, Virgilio ${ }^{8}$. La «imitación del antiguo», en este punto, es singularmente fiel, y los poetas dieciochescos encuentran en la temática bucólica un repertorio configurado a base de unos valores modélicos a los que plegarse -incluso vivencialmente: sociedad arcádica, Parnaso...- en un intento de buscar en la Antigüedad un código que sirva tanto para estructurar el discurso literario, como para configurar la ideología que conforme la conducta particular.

Esta recuperación, este reciclaje de una estructura formal -la égloga, principalmente- y de una ideología -informada de connotaciones míticas y utópicas ${ }^{-9}$ imprime a estas obras un nuevo sentido direccional de la escritura: se avanza cuanto más se retrocede; se es más moderno cuanto más fielmente se respeta una modelación arcaica. El prestigio de Roma ${ }^{10}$ y, en

7 Sobre la influencia de Teócrito y de sus Idilios vid. Tovar, A., «Presente y futuro de los estudios clásicos», en Ensayos y peregrinaciones (Madrid, 1960), 144 y ss. "...Los poetas bucólicos de las escuelas sevillana y salmantina, que encubrieron sus aventurillas, seguramente reprobables para el moralista, con la fermosa cobertura de las enseñanzas de este «corpus bucolicum» de este librito de pocas páginas [Los Idilios], pero tan importante, que tengo en la mano..."

- Casos concretos de la influencia de Virgilio en poetas bucólicos del siglo XVIII los han estudiado: Menéndez Pelayo, M., «Estudio preliminar», en Eglogas y Geórgicas de Virgilio (Madrid, 1879), XXXIX y XL (en el caso de Iglesias de la Casa); Demerson, G., «Sur une oeuvre perdue de Meléndez Valdés: la traduction de L'Eneide», Mélanges á Marcel Bataillon (Helsinki, 1962), 424-36 (en el caso de Meléndez); también, para la influencia de Virgilio en la obra de Meléndez, vid.: Rodríguez Moñino, «Prólogo», Poesías inéditas de Juan Meléndez Valdés (Madrid, 1954), 13 y 19. La admiración por Virgilio la testimonia Blanco White en su égloga El Mesías, donde escribe:

«Tu, soberano espíritu, que hiciste

anunciar otro tiempo al sacro vate.

Su bien al mundo, tú me inspiras ahora;

y su sagrado canto repetido

por mí será a los cándidos pastores..."

(cit. en Cueto, Poetas líricos del siglo XVIII, III (Madrid, 1971), 661. En lo que se refiere a otro poeta bucólico del siglo XVIII, Diego González, los motivos virgilianos que presentan muchas de sus composiciones han sido tratados en mi trabajo: La poesía pastoril de un poeta de la Segunda escuela poética salmantina, en Provincia de Salamanca (en prensa).

9 El componente utópico de la literatura dieciochesca española ha sido recientemente estudiado por: Alvarez de Miranda, P., «Sobre utopías y viajes imaginarios en el siglo XVIII español», en Homenaje a Gonzalo Torrente Ballester (Salamanca, 1981), 351-91.

10 Prestigio que alcanza a toda el área europea y que ha sido estudiado, en el terreno de las artes plásticas, por: Francastel, P., «La estética de las luces», en Arte, arqueología y estética en el siglo XVIII (Madrid, 1980), 51 y ss. y en otros aspectos culturales por: Olaechea, 
un segundo plano, el de Grecia y la grecidad ${ }^{11}$ se utilizan como modelizaciones que, tamizadas por la interpretación que de las mismas hicieran los humanistas del siglo XVI ${ }^{12}$, constituyen por entero el discurso bucólico dieciochesco.

La profunda entidad erótica y la identificación paganizante con las fuerzas de la naturaleza, que desde los textos bucólicos se realiza, son los dos más importantes vectores que organizan el entramado de la pastoral dieciochesca. Sin embargo, toda simplificación reductora es, en este terreno, radicalmente inoperante; sólo a través de la explicitación minuciosa de la compleja teoría de temas y motivos que confieren su entidad al género, es posible ипа intelección del mismo. Es únicamente desde el conocimiento de su articulación estructural, desde donde puede abrirse una vía de sentido que, al tiempo de alcanzar la trayectoria histórica del género, explique, desde él mismo, este momento - siglo XVIII- tan peculiar de su devenir.

Precisamente, ese conocimiento es el que exhiben las teorizaciones clásicas y también todas aquellas que se producen contemporáneamente a los textos bucólicos dieciochescos, ambas, desgraciadamente, a menudo olvidadas. Y es esta perspectiva -que nos suministra una teoría en términos generales «clásica»- la que nos permite asegurar que muchas de las actuales opiniones críticas sobre la bucólica del siglo XVIII han mediatizado, entorpeciéndola, la valoración, la lectura que este tipo de textos tiene en nuestro tiempo.

2. Desde luego, no puede decirse que la poesía específicamente bucólica de los finales del siglo XVIII haya tenido un tratamiento científico, por parte de quienes se han ocupado modernamente en la exoneración de la literatura de un siglo, sobre el que hasta hace poco se tenían prejuicios decimonónicos. Las reivindicaciones sucesivas de géneros y temáticas -singularmente aquellas que conocemos como «ilustradas», en términos genera-

R., Las relaciones hispanorromanas en la segunda mitad del siglo XVIII (Zaragoza, 1965) y por la reciente edición que del Epistolario de Azara Bodoni ha preparado Angelo Ciavarella (Roma, 1980).

1 Vid. Gil Fernández, L., Campomanes, un helenista en el poder (Madrid, 1976).

12 Estos humanistas, poetas y tratadistas, son, en cualquier caso, el referente inmediato que muchos escritores dieciochescos eligen, aun en la constancia de que aquellos, a su vez, remiten a un modelo clásico, generalmente virgiliano en lo que a la poesía pastoril se refiere. Vid. en este sentido, la introducción que Fernández de Rojas (Liseno) hace al frente de la edición póstuma de las obras de Diego González («Al que leyere»; primera edición: Madrid, 1796). 
les- no ha acabado nunca en alcanzar a la bucólica, seguramente por alcanzar ésta un carácter marcadamente «anticuario». Esta fidelidad al modelo clásico, que es una aspiración universal en los poetas de los que ahora hablamos, ha sido enfocada desde el siglo XIX desfavorablemente, quizá por suponerse que toda imitación lo es de un modelo en esencia irrepetible. En estas condiciones, y ya a priori, este tipo de poesía se encuentra «condenada» a parecer -como toda reactualización- esencialmente falsa y artificial, adjetivos estos que, como veremos, han sido utilizados con mucha frecuencia a la hora de describir los textos de tema pastoril.

De entre esta actitud generalizada, hay, en todo caso, que hacer una excepción. Desde el año 1953, por lo menos, una parte de la crítica -Del Río $^{13}$, Calvo Revilla ${ }^{14}$, Froldi ${ }^{15}$, Caso González ${ }^{16}$, Ciplijauskaite ${ }^{17}$, Palacios... ${ }^{18}$ - se ha esforzado por poner en evidencia un elemento innovador, «ilustrado», en la propia temática de la bucólica. Me refiero a ese «nuevo sentido del campo» que ciertas poesías bucólicas revelan ya cerca del final del siglo XVIII. Sin embargo, no toda la producción bucólica, es más, la inmensa mayoría de ella -como trataré de demostrar-, no puede quedar, por razones obvias, englobada dentro de la línea que J. I. Moreno ha llamado «fisiocratismo sentimentalizado» ${ }^{19}$. Muchas de las poesías de Meléndez (por lo menos hasta 1789); todas, por supuesto, las de Diego González, Iglesias de la Casa, Fernández de Rojas..., tienen como horizonte exclusivo el modelo clásico -Garcilaso, Virgilio, Teócrito...- en el que introducen tímidas exploraciones (églogas piscatorias ${ }^{20}$, venatorias, elogio real, pastoral fúnebre, perspectivismo femenino...) que, en cualquier caso, están integra-

13 «El sentimiento de la naturaleza en los Diarios de Jovellanos», Nueva Revista de Filología Hispánica, 7 (1953), 630-37.

14 «El nuevo sentido del campo en la poesía de Meléndez», Insula, 179 (1961), 6.

15 Un poeta iluminista: Meléndez Valdés (Milán, 1967), Cf. cap. V.

16 «El sentimiento de la naturaleza en Jovellanos», Poética de Jovellanos (Madrid, 1972), 156 y ss.

17 «Idealismo y realismo social en la poesía dieciochesca», Revista de Archivos, Bibliote. cas y Museos, 80 (1977), 443-53.

(18) «Estudio preliminar» a su edición de Poesías de Juan Meléndez Valdés (Madrid, 1979), 35 .

19 «Notas sobre la poesía del siglo XVIII. A propósito de los besos de amor de Meléndez Valdés», Estudios sobre literatura y arte dedicados al profesor Emilio Orozco Díaz, II (Granada, 1979), 468.

20 Vid. la reflexión que sobre este tipo de composiciones se encuentra en la anónima «Carta escrita al Editor de estas poesías", Poesías póstumas de D. José Iglesias de la Casa, I (1973), XIV. 
das en una tradicionalidad que las prevé y, hasta cierto punto, las determina.

La poesía de tipo bucólico ha sido tratada, con la excepción arriba marcada, como una etapa primeriza en la evolución hacia la conquista de unos nuevos valores -y de unas nuevas técnicas- que coinciden, en líneas generales, con las de la Ilustración. Estos análisis, sin embargo, insistían especialmente en la servidumbre que el género ostenta hacia un pasado periclitado-Edad de Oro, Arcadia...-; lo que se ha venido calificando como «Utopía idílica» ${ }^{21}$, «juegos de saloncitos sociales»22, «género convencional» ${ }^{23} \ldots$ es entendido, en definitiva, como una «modalidad desviada de la incorporación al nuevo racionalismo» ${ }^{24}$, herencia de una tradición latina que sirve, en España al menos, para recubrir el vacío dejado por las preocupaciones de la nueva ciencia.

Algunas otras apreciaciones comprometen aún más el valor que, desde la misma tradicionalidad del discurso literario, estamos dispuestos a prestarle a este género, realmente tan maltratado. Lázaro Carreter ha relacionado la temática pastoril con una falta de aptitud del siglo XVIII para la poesía y un proceso de enmascaramiento de todo lo «natural y verdadero» ${ }^{25}$. Para Avalle-Arce, la bucólica del XVIII -que no así la del siglo XVI, utilizada como parámetro clásico- tiene un carácter meramente evasivo de «tareas burócraticas» más pesadas ${ }^{26}$. Por otro lado, panteísmo egocéntrico y dolor cósmico, según Aguilar Piñal, vendrían a barrer como ideaciones poderosas la evasión pastoril, que de modo muy particular se potencia desde la Escuela salmantina entre los años 1773 y $1775^{27}$. El género queda,

21 Vid. Blanco Aguinaga, C.; Rodríguez Puertolas, J.; Zavala, I. M., Historia social de la Literatura española, II (Madrid, 1978), 58 y ss.

22 Vid. Prieto, A., Coherencia y relevancia textual (Madrid, 1981), 233 y ss.

23 Vid. Arce, J., La poesía del siglo ilustrado (Madrid, 1981), 22.

24 Vid. Lázaro Carreter, F., «Introducción» al Cotejo de las églogas que ha premiado la Real Academia de la Lengua (Salamanca, 1951), XIV.

25 «Introducción» al Cotejo..., XV y XVI.

26 La novela pastoril española (Madrid, 1975), 17.

27 «La poesía filosófica de Cándido María Trigueros», Revista de Literatura, 85 (1981), 21 y ss. Aguilar Piñal ha minimizado en exceso el papel que la bucólica juega en la configuración general de la lírica del siglo XVIII y, en particular, de la Escuela salmantina. El espacio por el crítico establecido -1773-75- queda ampliamente rebasado con la simple constancia de que ediciones como las de Iglesias de la Casa y fray Diego González, con una gran abundancia de temas pastoriles, aparecieron en 1793 y 1796, respectivamente. Tardía es también la fecha (1789) de la última poesía pastoril de Meléndez (la égloga El zagal del Tormes), en este sentido, 
pues, minimizado ${ }^{28} \mathrm{e}$, incluso, en una posición de franca inferioridad y dependencia de la pastoral renacentista ${ }^{29}$.

En otras ocasiones, ni siquiera alcanza la bucólica, para la crítica actual, el status de género, y así lo vemos englobado dentro de áreas más generales, como cuando I. Vallejo ha hablado de "poesía amorosa», para referirse a los poemas específicamente pastoriles de Diego González ${ }^{30}$, o, en una calificación ostensiblemente impropia, M. Raoux encuadra estos mismos poemas dentro de un cierto tipo de "poesía amatoria» ${ }^{31}$.

La descalificación del género -de la utilización que del mismo hacen los poetas de la segunda mitad del XVIII- se ha intentado justificar muchas veces desde su propia limitación cronológica (vid. n. 27) y, otras, desde su propio agotamiento como repetición de tópicos y clichés temáticos ${ }^{32}$. Según esta ûltima interpretación del devenir de las composiciones bucólicas, la vena satírico-burlesca, empeñada en levantar acta estrictamente realista del mundo campestre ${ }^{33}$, habría acabado muy pronto con la «corriente estilizada», creadora de una Arcadia de dilatados valores.

la epístola de Jovellanos a los arcades salmantinos no significó un viraje total en la orientación poética de estos. Después de la carta-poema (1776) se abre una opción hacia lo que se llama "poesía filosófica», que pronto es mayoritariamente abandonada. Incluso los poetas de la $2 .^{\text {a }}$ generación de la Escuela salmantina (Cienfuegos, Sánchez Barbero, Quintana...) se inician también con versos pastoriles, como ha puesto en evidencia A. Derozier en su «Introducción» a las Poesías completas de Quintana (Madrid, 1980), 125. Vid. también sobre este tema mi artículo en prensa: "Aportaciones al estudio de la Escuela poética salmantina (1773-1789)", Studia Philológica.

28 J. Arce, por ejemplo, no reconoce al género bucólico una autonomía y ni siquiera un carácter propio dentro de la lírica dieciochesca; lo estudia, en cambio, como un momento de la influencia garcilasista (Vid, La poesía..., 70 y ss.).

29 «Pero este bucolismo desbordado del último tercio del siglo XVIII, no es como el de Garcilaso o de Fray Luis, retiro de soledad y de pasión donde más honda y definitivamente suenan en el alma los momentos infinitos, sino delicioso campo de ensueños juveniles intrascendentes que llenan de voluptuoso placer los ánimos». (C. Real de la Riva, «La escuela poética salmantina del siglo XVIII», Boletín de la Biblioteca Menéndez Pelayo, 24 (1948), 358.

30 “Fray Diego Tadeo González», Archivo Agustiniano, 179 (1977), 54 y ss.

${ }^{3}$ Investigaciones acerca de fray Diego González (Memoire de Diplome D'etudes Superieures), 140. Sin publicar. Cito por la página del ejemplar mecanografiado que hay en el Instituto de Estudios Hispánicos de Lyon.

32 Vid. Ciplijauskaite, B., "Idilio y...», 447 y ss.

33 Torres Villarroel escribía sobre lo que era, ya en los comienzos del siglo XVIII, la Arcadia salmantina: «Sobre los pajizos céspedes del sucio Zurguén, negro borrón del purísimo cristal del Tormes, me recosté una tarde bien deseoso de saber algún viento...» (Los deshauciados del mundo y de la gloria -Madrid, 1979-, 64). 
Es de este modo como la fidelidad, la «imitatio» del modelo antiguo que intenta regenerarse desde la mentalidad neoclásica es valorado de modo negativo por una investigación atenta exclusivamente a un determinado esquema de progreso literario, que concibe las líneas maestras de su argumentación desde una postura no tan contemporánea como heredera de algunos prejuicios decimonónicos ${ }^{34}$. Desde esta óptica vemos cómo la bucólica se convierte en un género de tono lírico menor y, en todo caso, como intrascendente expresión de un deseo de distracción que intenta la imitación de la naturaleza ${ }^{35}$.

Otro tema, no tan marginal como pudiera pensarse, pues af ecta a las relaciones que arte y verdad mantienen, es el de la pretendida artificiosidad del género, su decidida vocación fictiva que tan combatida ha sido, por ejemplo, en el caso de los poemas bucólicos de Meléndez Valdés. Ya Alarcos, en su trabajo del año $26^{36}$, señalaba como primer defecto de los poemas de Batilo su artificiosidad y el empleo en ellos de manoseados (valdría decir irreales, tópicos) temas de la apacibilidad y dulzura. Juicios estos en los que había sido precedido por Salinas en la edición del año $25^{37}$, y que no sólo se mantienen sino que incluso han aumentado su tono crítico en una moderna edición, como la realizada por Palacios en $1980^{38}$. La sinceridad y el artificio, sus relaciones y variables, se han convertido en este último estudio - sintomático, sin duda, si tenemos en cuenta la proximidad de enfoque que presenta con las últimas tesis y trabajos dedicados a Jovellanos, Iglesias de la Casa, Fernández de Rojas...- en el eje de tensión sobre el que se sitúa una lectura moderna de los poemas bucólicos de Meléndez. En efecto, Palacios ha discutido el nivel de sinceridad que Meléndez ostenta en sus descripciones campestres, zanjando la cuestión de un modo por lo menos curioso ${ }^{39}$. El problema de la naturaleza está ya aquí

34 Véase, en este sentido, la dependencia que estos juicios presentan respecto a los famosos artículos de Espronceda, El pastor Clasiquinos, El Artista (1835) y Larra en un artículo de 19 de febrero de 1835 para la Revista Española.

35 Así se manifiesta M. R. Barabino en su tesis sobre Juan Fernández de Rojas (Fray Juan Fernández de Rojas: su obra y su significación en el siglo XVIII-Madrid, 1981-, 129 y ss.).

36 «Meléndez Valdés en la Universidad de Salamanca», Boletín de la Real Academia Española, 13 (1926), 161 y ss.

37 «La poesía de Meléndez Valdés», Poesías (Madrid, 1973), XXXIX.

38 Juan Meléndez Valdés. Poesías (Madrid, 1980), 7-43.

39 Escribe a propósito de esto: «Y, además, nadie le puede negar a un hombre del pueblo insuficiencia de imágenes.» («Estudio preliminar»), Juan Meléndez..., 35. 
contemplado por el crítico como una cuestión radicalmente separada del género desde el que esa naturaleza «se escribe». Esta proclividad a utilizar elementos exógenos a la entidad misma del poema ha sido, sin duda, uno de los factores que más han incidido en la nula valoración que al género bucólico se le concede hoy en día.

El problema ante composiciones como la Egloga 4. ${ }^{a}$ de Iglesias de la Casa ${ }^{40}$ o la Bucólica del Tormes, de Alvarez Cienfuegos ${ }^{41}$ se centra en cómo interpretar la sinceridad -y sus contrafiguras: lo artificioso, lo convencionalen el marco de una composición poética. Hablar de «sinceridad», de autenticidad a propósito de una descripción -expresión- paisajística es, como ha escrito Gombrich, emplear una metáfora ${ }^{42}$. Lo sincero funciona, para un ingenuo expresionismo, como aquello que se siente y se vive realmente. En este sentido tan estricto, una composición como el Llanto de Delio y Profecía de Manzanares de Delio ${ }^{43}$ no es, desde luego, sincera. Aunque por otra parte es sumamente difícil asegurar la existencia de un sentimiento falso y, en todo caso, esa no puede ser nunca la función que cumpla la investigación literaria.

A pesar de ello, el término «falsedad» se ha relacionado de todas las maneras posibles con el nivel de expresión de la bucólica dieciochesca. Esta expresión, como es sabido, puede funcionar como síntoma y como símbolo ${ }^{44}$. El defecto en que ha incurrido buena parte de la crítica en la valoración de este género, en esta época ${ }^{45}$, consiste en haber tomado como síntoma una expresión que tiene una configuración rigurosamente simbólica. En esta operación pueden ser percibidas claramente las vinculaciones que en ella existen con el pensamiento romántico y con la crítica positivista de finales del siglo pasado.

Romántico, porque todo análisis sobre nociones tan vagas como la de la «sinceridad», «verdad», etc., a propósito de un texto artístico, es heredero

40 En Poesías póstumas de Iglesias de la Casa (Salamanca, 1793), 140-44.

41 En Poesías, ed. José Luis Cano (Madrid, 1969), 197-200.

42 Meditaciones sobre un caballo de juguete (Barcelona, 1968), 39-43.

43 En Poesías del M. F. Diego González (Madrid, 1796), 1-18.

44 Para una interpretación moderna de las conexiones entre realidad y literatura, Vid., Talens, J., Elementos para una semiótica del texto artístico (Madrid, 1978), 17-60.

45 Ya hemos visto - n. 29- cómo esa misma crítica no emplea ya los mismos términos de «falsedad», "artificio»... al referirse a la bucólica del Renacimiento, que una mala interpretación hace suponer como más auténtica, menos tópica. 
de esta concepción según la cual el arte es una comunicación de emociones; síntoma de un estado anímico; expresión de una personalidad. Los textos sufren, desde esta perspectiva, una confrontación con la realidad física del individuo que los produce, generándose una concordancia (y el texto entonces es sincero) o un desajuste (y estamos ante la convencionalidad o el artificio).

Sin embargo, la percepción y valoración de las relaciones verdadexpresión de la misma, realidad/arte tiene que plantearse, forzosamente, desde el interior mismo de la comṕosición y desde su modelación comó parte de un género. Ninguna causa exógena puede o debe forzar un proceso contrastivo que el poema, la composición, por su misma naturaleza, rechaza: «El texto se cuenta a sí mismo», como escribe Barthes. En todo caso, y siempre referida a las composiciones de tipo pastoril, la sinceridad de las mismas no es más que la de la coherencia de su artificio; su fidelidad a la -tradición; su coordinación con el resto de los elementos; la sumisión de la parte al conjunto; el enmascaramiento de lo personal; la adecuación de las claves; la contención de la emoción...

Las composiciones bucólicas del siglo XVIII en su segunda mitad, utilizan -sabiamente, es preciso reconocerlo- expresiones: no son la expresión en sí mismas de ninguna personalidad. Hacer uso de expresiones codificadas y listas para ser empleadas en una tradición clasicista, en ello consiste eso que despectivamente se denomina "convencionalismo de lo pastoril»; sin ello, sin embargo, sería el mismo género como tal el que no existiría. Y es desde este convencionalismo, asumido como una más de las variadas actitudes que concurren a la resurrección del antiguo, cómo podemos entender una reflexión semiológica como la que actualmente ha realizado S. Sontag (Notes on Camp) sobre ese elemento -el campo, la naturaleza- que ocupa un puesto nuclear en la cultura de Occidente: «All camp objetcs, and persons, contain a large element of artifice.»

3. Las teorizaciones sobre la poesía bucólica son muy abundantes en toda la segunda mitad del siglo XVIII, sobre todo integradas como parte de prólogos o estudios introductorios a la reedición de algunas novelas pastoriles del Renacimiento. Este es el caso de Juan Antonio Mayáns y Siscar ${ }^{46}$, de Fermín Tadeo Villalpando ${ }^{47}$ o del mismo M. A. Rodríguez, que prepara el

46 Vid. su «Prólogo», a $E l$ pastor de Fílida (Valencia, 1792).

47 Vid. «Al Lector», en la edición a La Diana, de Montemayor, I (Madrid, 1795). 
prólogo a la primera edición de los Idilios de Gessner en castellano. Desde todos estos textos, cuya primera preocupación es la de resaltar cómo en la sociedad de finales del XVIII tiene absoluta cabida una poesía pastoril renovada, pero también fiel a las normas del género, se propone un modelo estilístico a seguir y se evidencia la importancia que este tipo de composiciones puede tener en el contexto global de la recuperación de lo clásico. La polémica que estos estudios proponen se centra en torno a la probable antigüedad de la bucólica ${ }^{48}$ y, sobre todo, en los orígenes de la misma. Orígenes acerca de los cuales Blair, y su traductor Munárriz, opinan que hay que situar en el refinamiento y la civilización ${ }^{49}$, mientras que Sánchez Barbero mantendrá que la bucólica es el producto más decantado de una Edad de Oro real ${ }^{50}$. Esta polémica, y otras de igual tenor que se suscitan, no son superfluas; resultan más bien momentos de una operación arqueológica completa que pretende reactualizar -abundan en ella las llamadas a realizar cierto tipo de innovaciones ${ }^{-51}$ un género, ciertamente desvirtuado por el lenguaje barroco ${ }^{52}$.

De otro lado, los llamados a la simplicidad y delicadeza ${ }^{53}$; a la expresión de lo conveniente e incluso convencional (Forner) ${ }^{54}$; a la «facilidad, ternura y suavidad» (Luzán $)^{55}$; a lo pastoril como ámbito tópico sometido a una rigurosa combinatoria (Blair ${ }^{56}$, no coinciden, desde luego, como posiciones teóricas, con los juicios mayoritariamente negativos que la crítica de

48 Herrera tenía a la poesía bucólica como «el más antiguo género de poesía» (vid. supra n. 4). Luzán participa de esta opinión, pero no así H. Blair-Lecciones sobre la retórica y las Bellas Letras, III (Madrid, 1800), 352.

49 Lecciones sobre..., 352 y ss.

50 Vid. Cap. V «De la poesía pastoril, idilio o égloga», Principios de poética. Ed. de A. A. Camus (Madrid, 1847), 175. Este tema no está totalmente resuelto por la investigación actual; Körte y Händel -La poesía helenística (Barcelona, 1973), 180-181- lo han tratado a propósito de los Idilios de Teócrito. Panofsky -El significado en las artes visuales (Madrid, 1980), n. 11, pág. 342- hace un balance bibliográfico del estado en que se encuentra la cuestión.

51 Vid., en este sentido, lo que Sánchez Barbero -Principios..., 175 y ss.- escribe a propósito de las innovaciones introducidas en la pastoral por Gessner. También, la reflexión de H. Blair-Lecciones sobre..., 366-sobre los inconvenientes de una «imitatio» servil.

52 Sobre el lenguaje de la pastoril como discurso habitado por el aliño y el decoro, y somo lenguaje, también, específicamente anticonceptista, Vid. Blair, H., Lecciones sobre..., 362 .

53 Vid. la anónima "Carta escrita...», Poesías póstumas de Iglesias..., X.

54 Vid. Cotejo de las églogas, 14.

55 Vid. Poética (Madrid, 1737), 182.

56 Lecciones..., III, 357-8. 
nuestro tiempo realiza sobre tales exigencias. Muy a menudo olvidadas, las palabras de Meléndez Valdés: «He procurado imitar a la naturaleza y hermosearla, siguiendo las huellas de la docta Antigüedad» ${ }^{57}$, hubieran debido servir para enfocar la problemática de este género, tan singularmente dieciochesco, una vez más desde el interior mismo del discurso literario.

Habría que recordar también aquí, cómo la consecución misma de las categorías que se manejan en este tipo de composiciones bucólicas (la sencillez, las maneras inocentes, la dulzura, la humildad, lo convencional, lo tierno) son el objeto en sí mismas de una búsqueda para la que Forner, por ejemplo, demandaba reglas ${ }^{58}$ y Sánchez Barbero proponía actitudes, que configuraban una teoría del posicionamiento que el escritor debía adoptar con respecto a la viabilidad de su texto:

«Sientan, más que reflexionen; pinten, no analicen; amen, pero sin furor.» ${ }^{59}$

Toda esta labor preceptiva, llevada a cabo en el siglo XVIII con respecto a la bucólica, tiene, y resulta obvio señalarlo, una fuerte apoyatura en la práctica (y también en la teórica en tránsito hacia el Barroco ${ }^{60}$ de la pastoral renacentista. Herrera, en primer lugar, suministra una codificación de materias, sentimientos, expresiones... que deben guiar al poeta bucólico ${ }^{61}$; pero cuando se contemplan en específico los temas y motivos temáticos que articulan la bucólica dieciochesca, esta dependencia del modelo renacentista -luisiano, en muchas ocasiones, garcilasista...- se manifiesta de modo todavía más evidente.

Los poetas bucólicos de la segunda mitad del XVIII mantienen este cordón umbilical que les une al soñado clasicismo. Lo hacen con una coherencia - con una «autenticidad»- que pone en juego tanto los resortes técnicos, como los modelos temáticos y hasta, ya en otro plano, las actitudes vitales, que se pliegan en un movimiento armónico-vida y poesía- a un convencionalismo superior y totalizador.

57 «Advertencia», a la edición de sus Poesías, en Cueto, L. A., Poetas líricos..., 87.

58 Cotejo..., 42.

59 Principios..., 177.

60 Para el estudio de la teoría pastoril en los preceptistas españoles-Pinciano, Cascales, Saavedra Fajardo...- hasta el siglo XVIII, Vid., López Estrada, F., Los libros de pastores en la literatura española (Madrid, 1974), 464 y ss.

61. Anotaciones..., 507 y ss. 
Evasión, artificio, convencionalidad es lo que, en otros términos, los teóricos del XVIII conocen como «saber plegarse perfectamente al nivel del género» ${ }^{62}$. $\mathrm{Y}$ es este género el que vemos desentrañarse en toda la extensión de su dispositivo retórico, que, teniéndose el mismo como referente -y en cierto sentido la pastoral dieciochesca es una metapoesía-, se da a sí mismo como un universo cerrado, cenacular ${ }^{63}$, impenetrable a una mirada crítica que utilice elementos extratextuales en su análisis.

Fernando R. DE LA FLOR Instituto Fray Luis de León (Salamanca)

62 «Carta escrita..., Poesias póstumas de José Iglesias..., XVII.

63 En el sentido en que lo utiliza M. Molho (Semántica y poética-Barcelona, 1978-, 97), cuando escribe: «Un rasgo de la literatura cenacular es que requiere la constitución de señas y contraseñas, es decir de uno o varios lenguajes por los que el cenáculo identifica a sus miembros.» 